\title{
Clinico-Hematological and cytogenetic spectrum of adult myelodysplastic syndrome: The first retrospective cross-sectional study in Iranian patients
}

Mostafa Paridar ${ }^{1}$, Kazem Zibara ${ }^{3}$, Seyed Esmaeil Ahmadi ${ }^{2}$, Abbas Khosravi ${ }^{4}$, Maral Soleymani ${ }^{6}$, Ebrahim Azizi ${ }^{5}$ and Omid Kiani Ghalesardi ${ }^{*}$ (1)

\begin{abstract}
Background: Myelodysplastic syndrome (MDS), a heterogeneous group of hematopoietic malignancy, has been shown to present different cytogenetic abnormalities, risk factors, and clinico-hematological features in different populations and geographic areas. Herein, we determined the cytogenetic spectrum and clinico-hematological features of Iranian MDS patients for the first time.
\end{abstract}

Methods: This prospective cross-sectional study was conducted on 103 patients with MDS in Ahvaz, southwest of Iran, from 2014 to 2018. Clinical presentations, complete blood counts (CBC), and bone marrow (BM) biopsy samples were assessed. Perls'staining was used to evaluate BM iron storage. The cytogenetic evaluation was performed using the conventional $\mathrm{G}$ banding method on the BM.

Results: Patients' median age was 62.3 (ranged from 50-76), and the majority were male (72.8\%). The most common clinical symptom at the time of admission was fatigue $(n=33)$ followed by pallor $(n=27)$. The most common subgroup was MDS-Multi Lineage Dysplasia (MDS-MLD) $(n=38,36.8 \%)$, followed by MDS-Single Lineage Dysplasia (MDS-SLD) $(n=28,18.4 \%)$. A normal karyotype was observed in 59 patients (57.3\%), while 44 patients $(42.7 \%)$ had cytogenetic abnormalities. Trisomy $8(+8)$ was the most common cytogenetic abnormality $(n=14)$ followed by del $17 p(n=9)$ and monosomy $7(-7)(n=7)$. Twelve patients $(11.65 \%)$ were transformed to AML.

Conclusion: Our data betokened that among our MDS patients, Trisomy 8 is the predominant cytogenetic abnormality, and MDS-MLD and MDS-SLD are the most common of subtypes. Noteworthy, the male: female ratio was slightly higher in Iran than in previous reports from other parts of the world. Our study is the first report of the clinical, hematological, and cytogenetic spectrum of MDS patients in Iran

Keywords: Myelodysplastic syndromes, Hematological spectrum, Cytogenetic, Iran

*Correspondence: omidkianis@gmail.com

2 Department of Hematology and Blood Banking, School of Allied Medicine, Iran University of Medical Sciences, Tehran, Iran

Full list of author information is available at the end of the article

\section{Introduction}

Myelodysplastic Syndromes (MDSs) are a group of hematopoietic disorders characterized by ineffective hematopoiesis, dysplasia of hematopoietic cells, and cytopenia in one or more blood cell lineages [1]. MDS generally occurs de novo; however, a small number of MDSs are secondary to radiation and/or chemotherapy

(c) The Author(s) 2021. Open Access This article is licensed under a Creative Commons Attribution 4.0 International License, which permits use, sharing, adaptation, distribution and reproduction in any medium or format, as long as you give appropriate credit to the original author(s) and the source, provide a link to the Creative Commons licence, and indicate if changes were made. The images or other third party material in this article are included in the article's Creative Commons licence, unless indicated otherwise in a credit line to the material. If material is not included in the article's Creative Commons licence and your intended use is not permitted by statutory regulation or exceeds the permitted use, you will need to obtain permission directly from the copyright holder. To view a copy of this licence, visit http://creativecommons.org/licenses/by/4.0/. The Creative Commons Public Domain Dedication waiver (http://creativecommons.org/ publicdomain/zero/1.0/) applies to the data made available in this article, unless otherwise stated in a credit line to the data. 
exposure. Pathophysiology of the disease includes multistep processes involving chromosomal abnormalities and/or genetic aberrations [2]. In the United States, MDS incidence is 3-4 per 100,000 annually and increases with age [3]. Usually, this disease is more prevalent in men than women, except for the $5 \mathrm{q}$ deletion subgroup, which is more common in women [4]. The disease course is very variable, ranging from an indolent to an aggressive state. However, it is often associated with an increased risk of acute myeloid leukemia (AML) transformation and a short survival rate [5]. Diagnosis of MDS transpires via scrutiny of the peripheral blood smear (PBS) and the bone marrow (BM). Pancytopenia and single or multilineage dysplasia are observed in the $\mathrm{PB}$, whereas less than $20 \%$ blasts and hematopoietic cells dysplasia are detected in the BM. Based on the 2016 classification of the World Health Organization (WHO), MDS comprises six subgroups, including MDS with multilineage dysplasia (MDS-MLD), MDS with single lineage dysplasia (MDSSLD), MDS with ring sideroblasts (MDS-RS), MDS with excess blasts (MDS-EB -1 and 2), MDS with isolated del (5q), and unclassifiable MDS (MDS-U) [6].

Cytogenetic abnormalities such as amplifications, deletions, and translocations have been detected in about $50 \%$ of patients with de novo MDS and $80 \%$ of patients with secondary MDS, as well [7]. Evaluation of cytogenetic abnormalities is useful in the diagnosis of MDS and crucial in determining the prognosis [8]. Indeed, the chromosomal abnormality type is one of the most important factors employed in the MDS Revised International Prognostic Scoring System (R-IPSS) [9]. Patient prognosis helps determine the disease's clinical course and plays a vital role in establishing the patient's therapeutic plan [10].

There are many reports from western countries in terms of cytogenetic profiles of MDS patients. However, clinical symptoms, cytogenetic abnormalities, and the disease's pathophysiology are dissimilar in different populations and vary greatly in different geographic areas. Therefore, the current study aimed to determine the cytogenetic spectrum and clinico-hematological features of MDS patients in the Khuzestan province, southwest of Iran. This is the first comprehensive report from Iranian MDS patients.

\section{Material and methods \\ Patients and study design}

This prospective cross-sectional study was conducted on 103 patients with MDS referred to Shafa Hospital in Ahvaz, southwest of Iran, from 2014 to 2018. Patients diagnosed as de novo MDS according to their clinical and hematological findings were included in the study. Notably, we excluded patients with cytopenia due to other non-malignant disorders and patients with a history of chemotherapy or radiotherapy. All patients were diagnosed and classified according to the classification of myeloid neoplasms and acute leukemia of the 2016 revision of the World Health Organization [6]. This study was approved by the Ethics Committee of Ahvaz Jundishapur University of Medical Sciences. Signed consent forms were received from all the patients prior to participation in the study.

\section{Hematological assessments}

Following the clinical examination, complete blood counts $(C B C)$ were performed, and PBS was scrutinized. Patients suspected of having MDS were subjected to further evaluation by BM biopsy samples obtained from the posterior superior iliac spine. According to the manufacturer's protocol, assessment of Iron was performed on the BM using the Perls' stain kit (Sigma-Aldrich).

\section{Cytogenetic analysis}

The cytogenetic evaluation was performed using a conventional $\mathrm{G}$ banding method on the BM samples. First, BM cells were cultured for $24 \mathrm{~h}$ in $5 \mathrm{ml}$ of Marrowmax medium, 20\% FBS, $2 \mathrm{mg}$ L-glutamine, and $100 \mathrm{ml} / \mathrm{U}$ penicillin/streptomycin. Afterward, a total of $50 \mu \mathrm{l}$ of colcemid $(10 \mu \mathrm{g} / \mathrm{ml})$ was added to the culture medium, and cells were incubated for $20 \mathrm{~min}$ at $37^{\circ} \mathrm{C}$. Following this, a hypotonic potassium chloride solution was added to the cells which were incubated for $25 \mathrm{~min}$ at $37{ }^{\circ} \mathrm{C}$. CELLS were then fixed with methanol:acetic acid (3:1), and slides of metaphase chromosomes were prepared in a humidified and controlled temperature environment. Metaphase chromosomes (at least 20 metaphases) were banded using the Giemsa trypsin banding (GTG) method, and karyotypes were defined according to the International System for Human Cytogenetic Nomenclature (ISCN) 2013 criteria.

\section{Statistical analysis}

Data are displayed as mean values, while the standard error of the mean was shown using error bars (Mean \pm SEM). GraphPad Prism (Version 8.0.1.244, San Diego, CA, USA) software was utilized to perform statistical analyses.

\section{Results}

\section{Patients characteristics}

Among 300 patients originally referred to the hospital, a total of 103 patients were diagnosed as de novo MDS according to their clinical and hematological tests and hence were included in the study. Patients' median age was 62.3 years (50-76), and the majority of patients were of male (72.8\%). The mean levels of hemoglobin $(\mathrm{Hb})$, 
platelets (plt), and white blood cells (WBC) were $9.9 \mathrm{~g} / \mathrm{dl}$, $103 \times 10^{3} / \mu \mathrm{l}$, and $3.4 \times 10^{3} / \mu \mathrm{l}$; respectively (Table 1 ).

More than $75 \%$ of the patients presented hypercellular BM. Moreover, iron storage was increased in 86 cases $(83.5 \%)$ (Table 1$)$. The major clinical symptom at the time of admission was fatigue $(\mathrm{n}=33)$ followed by pallor $(n=27)$, easy bruising and bleeding $(n=20)$, recurrent infections $(n=19)$, and bone pain $(n=4)$. Finally, a total of twelve patients $(11.65 \%)$ were transformed to AML. Based on FAB classification, 4, 6, and 2 patients progressed to AML-M0, AML-M1, and AML-M2, respectively.

\section{Patients classification}

The patients were classified into different subgroups according to the 2016 revision of the WHO classification.

Table 1 Patients' characteristics

\begin{tabular}{lll}
\hline Gender & Male & $\mathbf{7 5}(\mathbf{7 2 . 8 1 \% )}$ \\
& Female & $\mathbf{2 8 ( 2 7 . 1 9 \% )}$ \\
\hline Age (years) & Median (range) & $62.3(50-76)$ \\
Work history & Agriculturist & $23(22.33 \%)$ \\
& Petroleum worker & $7(6.79 \%)$ \\
& Truck driver & $5(4.85 \%)$ \\
Hemoglobin $(\mathrm{g} / \mathrm{dl})$ & Others & $68(66 \%)$ \\
Platelet $\left(\times 10^{3} / \mu \mathrm{l}\right)$ & Median \pm SD & $9.9 \pm 1.1$ \\
WBC $\left(\times 10^{3} / \mu \mathrm{l}\right)$ & Median \pm SD & $103 \pm 20$ \\
ANC $\left(\times 10^{3} / \mu \mathrm{l}\right)$ & Median $\pm S D$ & $3.4 \pm 0.5$ \\
BM cellularity & Median $\pm S D$ & $1.6 \pm 0.3$ \\
& Hypercellular & $78(75.73 \%)$ \\
BM Iron storage & Normocellular & $18(17.47 \%)$ \\
& Hypocellular & $7(6.8 \%)$ \\
& Increased & $86(83.5 \%)$ \\
& Decreased & 0 \\
\hline
\end{tabular}

WBC white blood cells, $A N C$ absolute neutrophil count, $B M$ bone marrow
The most common subgroup was MDS-MLD $(\mathrm{n}=38$, $36.8 \%)$ followed by MDS-SLD $(\mathrm{n}=28,18.44 \%)$. However, the rarest subgroup was MDS-RS $(n=3,2.91 \%)$ (Table 2).

\section{Patients karyotypes}

Concerning the karyotypes of the patients, a total of 59 patients $(57.28 \%)$ presented a normal karyotype, while the remaining 44 patients $(42.72 \%)$ had cytogenetic abnormalities (Fig. 1a). Patients with abnormal karyotype showed different types of abnormalities. Single, double and complex abnormalities were observed in 32 (72.7\%), 9 (20.5\%) and 3 (6.5\%) patients; respectively (Fig. 1b). The distribution of normal and abnormal karyotypes among MDS subgroups is demonstrated in Fig. 1c. On the other hand, the most common cytogenetic abnormality among the 44 MDS patients was Trisomy $8(+8)(n=14)$, followed by del $17 \mathrm{p}(\mathrm{n}=9)$ and monosomy $7(-7)(\mathrm{n}=7)$ (Fig. 2). The prevalence and distribution of the chromosomal abnormalities in MDS patients are detailed in Fig. 2.

\section{Patients prognosis}

The patients' prognosis was assessed according to the Revised International Prognostic Scoring System [R-IPSS]. Results showed that a total of 68 patients (66\%) were considered as good or very good prognosis (Table 3). Moreover, 26 cases (25.2\%) showed an intermediate prognosis. However, a poor prognosis was observed in 9 cases $(8.7 \%)$, while none of the patients showed very poor prognosis (Table 3 ).

\section{Discussion}

MDS is a heterogeneous clonal disorder associated with ineffective hematopoiesis, reduced blood cells, and hematopoietic cells' dysplasia. Generally, MDS is known as a preleukemic disorder and is considered an elderly disease. Indeed, the mean age of patients in our study was 66 years, with a range of $50-76$ years, which is similar

Table 2 Patients' subgroups based on WHO Classification 2016

\begin{tabular}{|c|c|c|c|c|}
\hline Subgroups & & Number of patients & Normal cytogenetics & $\begin{array}{l}\text { Abnormal } \\
\text { cytogenetics }\end{array}$ \\
\hline MDS-MLD & & 38 (36.89\%) & 22 & 16 \\
\hline MDS-SLD & & $28(18.44 \%)$ & 17 & 11 \\
\hline \multirow[t]{2}{*}{ MDS-EB } & MDS- EB-1 & $15(14.56 \%)$ & 11 & 4 \\
\hline & MDS-EB -2 & $11(10.67 \%)$ & 5 & 6 \\
\hline MDS with isolated del(5q) & & $4(3.88 \%)$ & 0 & 4 \\
\hline MDS-RS & & $3(2.91 \%)$ & 1 & 2 \\
\hline MDS-U & & $4(3.88 \%)$ & 3 & 1 \\
\hline
\end{tabular}

MDS-MLD MDS with multilineage dysplasia, MDS-SLD MDS with single lineage dysplasia, MDS-EB MDS with excess blasts, MDS-RS MDS with ring sideroblasts, MDS-U MDS unclassifiable 


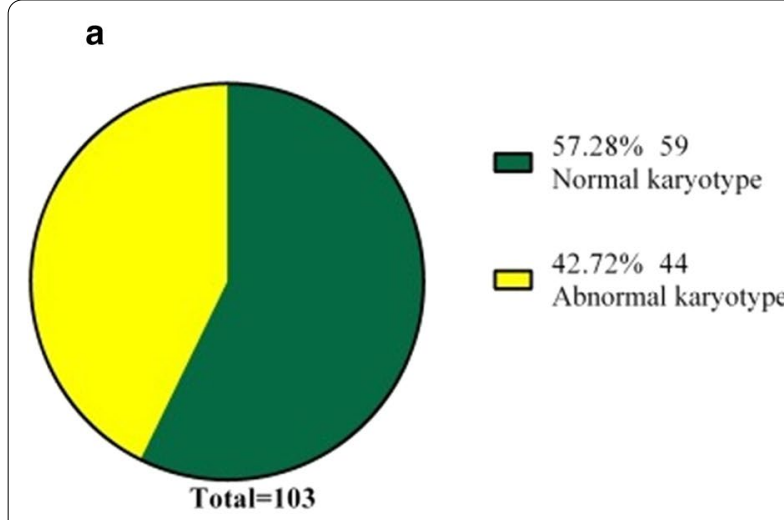

b

C

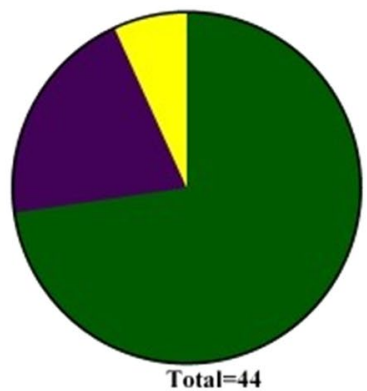

$72.73 \% 32$ single abnormality $20.45 \% 9$ duble abnormalites $6.82 \% 3$ complex karyotype

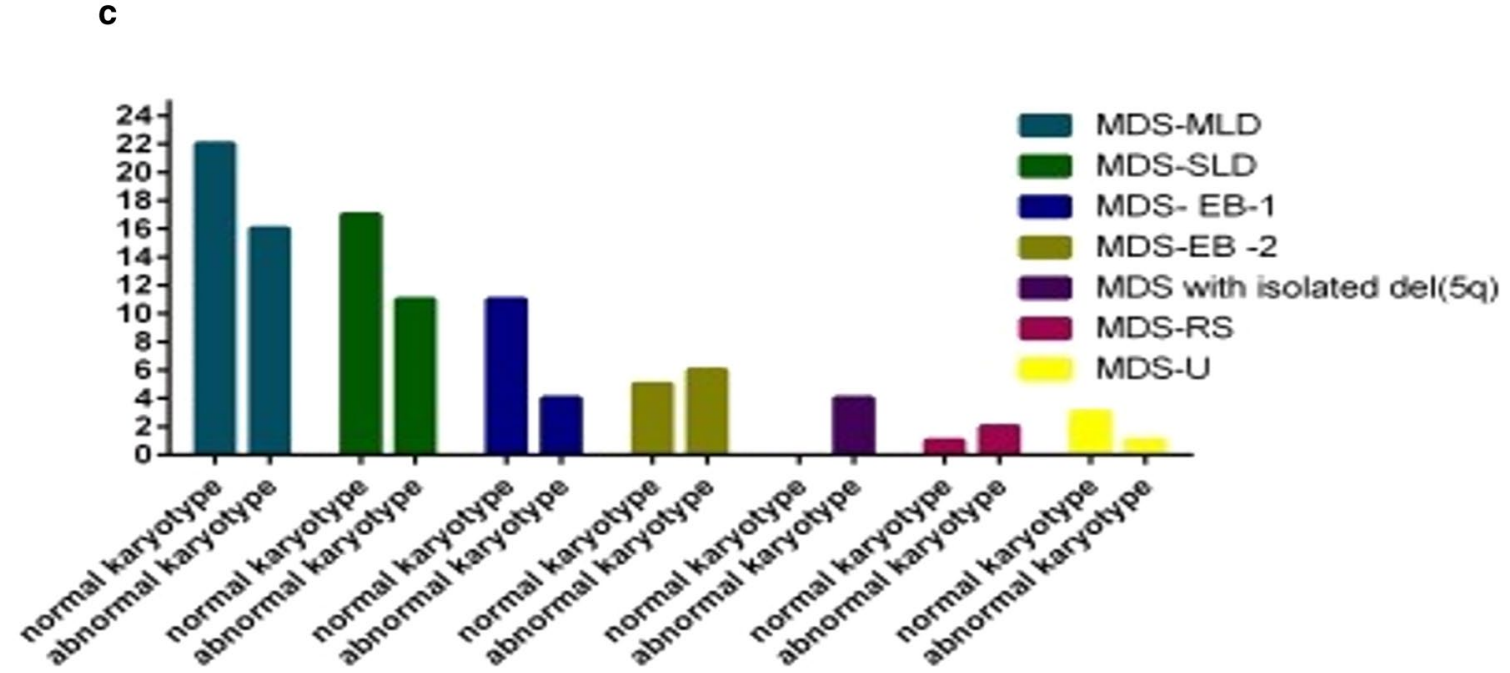

Fig. 1 Prevalence of the cytogenetic abnormalities observed in MDS patients. a Prevalence of normal and abnormal karyotypes among MDS patients. $\mathbf{b}$ Types of abnormalities among patients with abnormal karyotype. $\mathbf{c}$ Distribution of normal and abnormal karyotypes among MDS subgroups

to MDS in the US population (67 years) [11], and close to Turkey (69 years) [12] and European countries such as Germany (70 years) [13] and Poland [14] (70 years). On the other hand, our results are significantly different from those of East Asian countries such as China (49 years) [15], India $(42,45$, and 55 years) [16-18], and Japan (76 years) [19]. Most of the patients were farmers or worked in petroleum jobs. It is worth noting that most of the farmers in the southwest regions of Iran, where our study was conducted, are exposed to pesticides. The association of pesticide exposure and MDS incidence was recently confirmed in a meta-analysis study [20]. Moreover, many investigators reported that petroleum workers exposed to benzene had an important MDS risk factor $[21,22]$. The male to female ratio was $2.6: 1$, which was clearly higher than those reported from the US (1.9: 1) [11], Korea (1.7: 1) [23], China (1.3: 1) [15], and Pakistan (1.7: 1) [24]. In Iranian culture, women do not work as much as men, especially the high-risk jobs, which might explain the higher male: female ratio in our study compared to other reports.

The mean hemoglobin level in our study on southwest Iranian patients was $9.9 \mathrm{~g} / \mathrm{dl}$, which is similar to that obtained in Turkey $(9 \mathrm{~g} / \mathrm{dl})$ [12] and Greece $(9.5 \mathrm{~g} / \mathrm{dl})$ [25]. However, our hemoglobin data are higher than those obtained in Pakistan (7.7 g/dl), China (6.3 g/dl) [15], Singapore $(7.7 \mathrm{~g} / \mathrm{dl})$ [26], and India $(6.84 \mathrm{~g} / \mathrm{dl})$ [18]. The difference may be due to the higher percentage of males in our study and the fact that Iran implements a national iron supplementation program. On the other hand, the mean platelet counts in our study was $103 \times 10^{3} / \mu \mathrm{l}$, which is similar to those obtained by Lau et al. in Singapore $\left(101 \times 10^{3} / \mu \mathrm{l}\right)$ [26]. However, our data on platelets counts are higher than those obtained by Chen et al. in China $\left(42 \times 10^{3} / \mu \mathrm{l}\right)$ [15], Ehsan et al. in Pakistan $\left(60 \times 10^{3} / \mu \mathrm{l}\right)$, and Chaubey et al. in India $\left(85 \times 10^{3} / \mu \mathrm{l}\right)[18]$. Noteworthy 


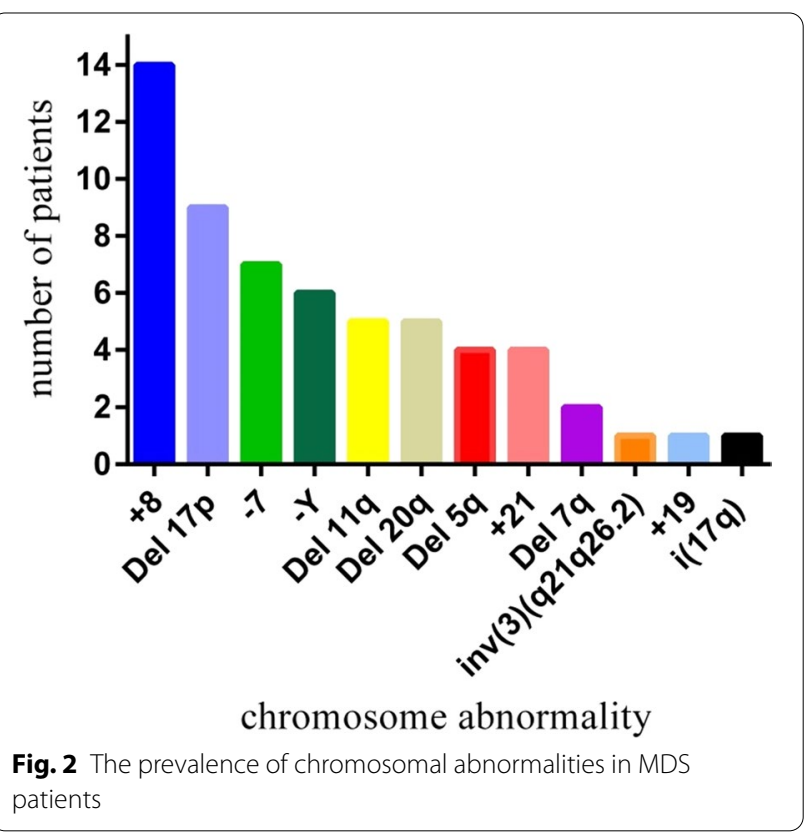

that even higher platelet counts were reported in Turkey $\left(163 \times 10^{3} \mu \mathrm{l}\right)[12]$ and Greece $\left(158 \times 10^{3} / \mu \mathrm{l}\right)[25]$.

Although our study included patients from the 2014 to 2018 period, all patients were re-classified according to the 2016 revision of the World Health Organization classification of myeloid neoplasms and acute leukemia [6]. Our data showed that the most common MDS subgroup was MDS-MLD (36.9\%), followed by MDS-SLD (18.4\%). These results are in line with those of Haase et al. in Germany [27] and Rashid et al. in Pakistan [28], who reported that MDS-MLD is the most common subtype $(27.6 \%$ and $52.1 \%$, respectively). Moreover, Pozdnyakova et al. in the USA [11] and Li et al. in China [29] reported that MDS-MLD was the most common subgroup (Respectively $32.2 \%$ and $44 \%$ ) followed by MDS-EB-I. In contrast, Chauby et al. reported MDS-SLD as the most common type of MDS in India [18]. The aforementioned differences might be due to the different ethnicity, population of the study, and/or sensitivity of the applied laboratory assay.

Cytogenetic abnormalities play a substantial role in the pathogenesis of MDS and are key factors in the diagnosis, classification, and prognostic scoring of the disease. However, the pathogenesis of MDS is still not well understood in Iran. The environmental, occupational, and genetic factors in Iran's southwest region are very different from western countries. This would affect the pathogenesis of MDS and may cause various chromosomal abnormalities, different frequencies, and patterns of MDS subtypes. Chromosomal abnormalities were observed in $42.7 \%$ of the patients, in accordance to other studies conducted in different parts of the world such as in Pakistan (42.3\%) [28], the United States (44.5\%) [11], Germany (49.8\%) [27], Tunisia (51\%) [30], and India (47.5\%) [18]. However, this was less than what was found in China (67.5\%) [29]. In particular, $41.7 \%, 29.5 \%$, and $28.8 \%$ of the reported chromosomal abnormalities were related to copy number only, structural abnormalities, and concomitant occurrence of both, respectively [29]. Among patients with abnormal karyotypes, $72.7 \%$ had a single abnormality, $20.5 \%$ had double abnormalities, while $6.8 \%$ had complex abnormalities (more than 3 abnormalities). The prognostic score of the studied patients was assessed according to R-IPSS. Accordingly, more than $91.3 \%$ of patients had very good, good, and intermediate prognosis. However, the poor prognosis was observed in only 9 cases, and very poor prognosis was observed in none of the patients.

Table 3 Cytogenetic score groups based on R-IPSS

\begin{tabular}{|c|c|c|c|c|c|c|c|c|c|}
\hline \multirow{2}{*}{$\begin{array}{l}\text { Cytogenetic } \\
\text { prognosis } \\
\text { subgroup }\end{array}$} & \multirow[t]{2}{*}{ Cytogenetic abnormality } & \multirow[t]{2}{*}{ Total } & \multicolumn{7}{|c|}{ MDS subtypes } \\
\hline & & & MDS-SLD & MDS-MLD & MDS-EB-1 & MDS-EB-2 & MDS with del (5q) & MDS-RS & MDS-U \\
\hline Very good & $-y$, del $11 q$ & 3 & $\begin{array}{l}2 \\
(7.1 \%)\end{array}$ & $\begin{array}{l}1 \\
(2.6 \%)\end{array}$ & 0 & 0 & 0 & 0 & 0 \\
\hline \multirow[t]{2}{*}{ Good } & Normal & 59 & $17(60.7 \%)$ & $22(57.9 \%)$ & $11(73.3 \%)$ & $5(43.5 \%)$ & 0 & $1(33.3 \%)$ & $3(75 \%)$ \\
\hline & del5q, del20q & 6 & $\begin{array}{l}1 \\
(3.5 \%)\end{array}$ & $\begin{array}{l}1 \\
(2.6 \%)\end{array}$ & 0 & 0 & $4(100 \%)$ & 0 & 0 \\
\hline Intermediate & $\begin{array}{l}+8,+19, \text { del } 7 q \text {, } i(17 q) \text {, other } \\
\text { single/double abnormalities }\end{array}$ & 26 & $8(28.6 \%)$ & $11(28.9 \%)$ & $\begin{array}{l}3 \\
(20 \%)\end{array}$ & $\begin{array}{l}1 \\
(9.1 \%)\end{array}$ & 0 & $2(66.7 \%)$ & $1(25 \%)$ \\
\hline Poor & $\begin{array}{l}\text {-7, inv (3), double includ- } \\
\text { ing }-7 / \text { del(7q) and complex } \\
\text { (3 abnormalities) }\end{array}$ & 9 & 0 & $\begin{array}{l}3 \\
(7.9 \%)\end{array}$ & $\begin{array}{l}1 \\
(6.6 \%)\end{array}$ & $5(45.5 \%)$ & 0 & 0 & 0 \\
\hline Very poor & $>3$ abnormalities & 0 & 0 & 0 & 0 & 0 & 0 & 0 & 0 \\
\hline
\end{tabular}


In this study, the most common chromosomal abnormality was trisomy 8 (13.6\% of all patients and $31.8 \%$ of patients with abnormal karyotype), followed by del $17 \mathrm{p}$ (8.7\% of all patients and $20.5 \%$ of patients with abnormal karyotype). Trisomy 8 was observed in 10 patients as a single chromosomal abnormality, in 2 patients with double chromosomal abnormalities, and in 2 patients with a complex karyotype. In accordance, Li et al. in China [29] and Rashid et al. in Pakistan [28] showed that the most common chromosomal abnormality was trisomy 8. In contrast, the most common chromosomal abnormality in Tunisia [30], Germany [27], Switzerland [31], Greece [25], and the United States [11] was - 5/del (5q). Our results showed that chromosomal abnormalities in Iranian MDS patients often include changes in the copy number (except for 2 cases), including deletion of all or part of a chromosome (e.g., del 17p or monosomy 7) or gain of a chromosome (e.g., trisomy 8), while balance abnormalities (such as translocations) have a very low incidence in patients. The changes in copy numbers result in a change in the dosage of genes, which can lead to the inactivation of tumor suppressor genes and the activation of oncogenes by various mechanisms such as haploinsufficiency and loss of heterozygosity, thus playing an essential role in the initiation and progression of the disease. For instance, it has been shown that the CUX1 gene, expressed on chromosome 7, acts as a tumor suppressor gene in myeloid precursors, decreases in MDS (and AML) with - 7/del (7q), and is involved in the pathogenesis of the disease [32]. It is worth noting that MDS cells with trisomy $8(+8)$ express high levels of antiapoptotic proteins and have high resistance to apoptotic agents, such as gamma rays [33].

There has not been such a registry developed to capture the MDS epidemiology in Iran yet. So, we will be the pioneer to report the Clinico-Hematological and cytogenetic spectrum of adult myelodysplastic syndrome in addition to the plethora of scientific information that is already available in the western and eastern literature. It is worth mentioning that cytogenetics mainly aims to identify recurrent karyotypic alterations which are termed clonal chromosomal aberrations (CCAs), while non-clonal chromosome aberrations (NCCAs) might also play an intriguing role [34, 35]. Recently NCCAs have drawn more attention, so it would be interesting to include NCCA data for future studies, especially for patients who did not display clonal chromosome aberrations.

\section{Conclusion}

Our data indicated that MDS-MLD and MDS-SLD are the most common subtypes of MDS in Iran's southwest region. In addition, Trisomy 8 was the most predominant cytogenetic abnormality. Moreover, our results showcased that the male: female ratio is slightly higher than previous reports from other parts of the world. This study represents the first report of the clinical, hematological, and cytogenetic spectrum of MDS patients in Iran. This study's major limitations are that patients' overall survival, treatment strategies, and response to treatment were not evaluated and suggested to be resolved in future studies.

\section{Abbreviations}

MDS: Myelodysplastic syndrome; CBC: Complete blood counts; BM: Bone marrow; AML: Acute myeloid leukemia; PBS: Peripheral blood smear; WHO: World Health Organization; MDS-MLD: MDS-multi lineage dysplasia; MDS-SLD: MDSsingle lineage dysplasia; MDS-RS: MDS with ring sideroblasts; MDS-EB: MDS with excess blasts; MDS-U: Unclassifiable MDS; R-IPSS: Revised international prognostic scoring system; GTG: Giemsa trypsin banding; ISCN: International system for human cytogenetic nomenclature.

\section{Acknowledgements \\ We wish to thank all our colleagues in Shafa Hospital, Ahvaz, Iran.}

\section{Authors' contributions}

OKG designed the study. MP, OKG, AK, SEA, MS, and EA carried out the experiments. KZ analyzed the data. MP and KZ wrote the paper. SEA validated and edited the paper. All authors discussed the results and commented on the manuscript. All authors read and approved the final manuscript.

\section{Funding}

Not available.

\section{Availability of data and materials}

The datasets used and analyzed during this study are available from the corresponding author on reasonable request.

\section{Declarations}

Ethics approval and consent to participate

All procedures have been approved by the appropriate ethics committee and have therefore been performed in accordance with the ethical standards laid down in the 1964 Declaration of Helsinki and its later amendments.

Consent for publication

Informed consent was signed prior to participation in the study.

\section{Competing interests}

The authors declared no conflict of interest.

\section{Author details}

${ }^{1}$ Deputy of Education, Ministry of Health and Medical Education, Tehran, Iran. ${ }^{2}$ Department of Hematology and Blood Banking, School of Allied Medicine, Iran University of Medical Sciences, Tehran, Iran. ${ }^{3}$ PRASE, Biology Department, Faculty of Sciences-I, Lebanese University, Beirut, Lebanon. ${ }^{4}$ Transfusion Research Center, High Institute for Research and Education in Transfusion 
Medicine, Tehran, Iran. ${ }^{5}$ Research Center for Thalassemia and Hemoglobinopathy, Health Institute, Ahvaz Jundishapur University of Medical Sciences, Ahvaz, Iran. ${ }^{6}$ Student Research Committee, Ahvaz Jundishapur University of Medical Sciences, Ahvaz, Iran.

Received: 1 March 2021 Accepted: 28 April 2021 Published online: 08 May 2021

\section{References}

1. Shahrabi S, Khosravi A, Shahjahani M, Rahim F, Saki N. Genetics and epigenetics of myelodysplastic syndromes and response to drug therapy: new insights. Oncol Rev. 2016;10(2):311.

2. Shallis RM, Ahmad R, Zeidan AM. The genetic and molecular pathogenesis of myelodysplastic syndromes. Eur J Haematol. 2018;101(3):260-71.

3. Goldberg SL, Chen E, Corral M, Guo A, Mody-Patel N, Pecora AL, et al. Incidence and clinical complications of myelodysplastic syndromes among United States Medicare beneficiaries. J Clin Oncol Off J Am Soc Clin Oncol. 2010;28(17):2847-52.

4. MaX. Epidemiology of myelodysplastic syndromes. Am J Med. 2012;125(7 Suppl):S2-5

5. Montalban-Bravo G, Garcia-Manero G. Myelodysplastic syndromes: 2018 update on diagnosis, risk-stratification and management. Am J Hematol. 2018;93(1):129-47.

6. Arber DA, Orazi A, Hasserjian R, Thiele J, Borowitz MJ, Le Beau MM, et al. The 2016 revision to the World Health Organization classification of myeloid neoplasms and acute leukemia. Blood. 2016;127(20):2391-405.

7. Paridar M, Ghalesardi OK, Seghatoleslami M, Ahmadzadeh A, Khosravi A, Saki N. Cytogenetic and molecular basis of BCR-ABL myelodysplastic syndrome: diagnosis and prognostic approach. J Cancer Metastasis Treat. 2017;3(2):38-44.

8. Ghale-sardi OK, JalaliFar MA, Khodadi E, Ahmadzadeh A, Saki N. BCR/ABL analysis in myelodysplastic syndromes. Comp Clin Pathol. 2018:27(2):379-84.

9. Greenberg PL, Tuechler H, Schanz J, Sanz G, Garcia-Manero G, Sole F, et al. Revised international prognostic scoring system for myelodysplastic syndromes. Blood. 2012;120(12):2454-65.

10. Steensma DP. Myelodysplastic syndromes current treatment algorithm 2018. Blood Cancer J. 2018;8(5):47.

11. Pozdnyakova O, Miron PM, Tang G, Walter O, Raza A, Woda B, et al. Cytogenetic abnormalities in a series of 1029 patients with primary myelodysplastic syndromes: a report from the US with a focus on some undefined single chromosomal abnormalities. Cancer. 2008;113(12):3331-40.

12. Demirkan F, Alacacioglu I, Piskin O, Ozsan HG, Akinci B, Ozcan AM, et al. The clinical, haematological and morphological profile of patients with myelodysplastic syndromes: a single institution experience from Turkey. Leuk Lymphoma. 2007:48(7):1372-8.

13. Gattermann N, Kundgen A, Kellermann L, Zeffel M, Paessens B, Germing $U$. Diagnosis and therapy of myelodysplastic syndromes in Germany: a retrospective multicenter analysis. Onkologie. 2012;35(6):350-6.

14. Madry K, Machowicz R, Waszczuk-Gajda A, Drozd-Sokolowska J, Holowiecka BS, Wiater E, et al. Demographic, Hematologic, and clinical features of myelodysplastic syndrome patients: results from the first polish myelodysplastic syndrome registry. Acta Haematol. 2015;134(2):125-34.

15. Chen B, Zhao WL, Jin J, Xue YQ, Cheng X, Chen XT, et al. Clinical and cytogenetic features of 508 Chinese patients with myelodysplastic syndrome and comparison with those in Western countries. Leukemia. 2005; 19(5):767-75.

16. Chatterjee T, Dixit A, Mohapatra M, Tyagi S, Gupta PK, Mishra P, et al. Clinical, haematological and histomorphological profile of adult myelodysplastic syndrome. Study of 96 cases in a single institute. Eur J Haematol. 2004;73(2):93-7.

17. Dakshinamurthy AG, Novitzky N, Bharadwaj R, Prakhya BM. Cytogenetic analysis of 52 Indian patients with de novo myelodysplastic syndromesa comparative analysis of results with reports from Asia. Ann Hematol. 2005;84(5):298-303.
18. Chaubey R, Sazawal S, Dada R, Mahapatra M, Saxena R. Cytogenetic profile of Indian patients with de novo myelodysplastic syndromes. Indian J Med Res. 2011;134:452-7.

19. Chihara D, Ito H, Katanoda K, Shibata A, Matsuda T, Sobue T, et al. Incidence of myelodysplastic syndrome in Japan. J Epidemiol. 2014;24(6):469-73.

20. Jin J, Yu M, Hu C, Ye L, Xie L, Jin J, et al. Pesticide exposure as a risk factor for myelodysplastic syndromes: a meta-analysis based on 1942 cases and 5359 controls. PLOS ONE. 2014;9(10):e1 10850.

21. Khalade A, Jaakkola MS, Pukkala E, Jaakkola JJ. Exposure to benzene at work and the risk of leukemia: a systematic review and meta-analysis. Environ Health. 2010;9(1):31.

22. Schnatter AR, Glass DC, Tang G, Irons RD, Rushton L. Myelodysplastic syndrome and benzene exposure among petroleum workers: an international pooled analysis. J Natl Cancer Inst. 2012;104(22):1724-37.

23. Lee JH, Lee JH, Shin YR, Lee JS, Kim WK, Chi HS, et al. Application of different prognostic scoring systems and comparison of the FAB and WHO classifications in Korean patients with myelodysplastic syndrome. Leukemia. 2003;17(2):305-13.

24. Sultan S, Irfan SM. Adult primary myelodysplastic syndrome: experience from a tertiary care center in Pakistan. Asian Pac J Cancer Prev APJCP. 2016;17(3):1535-7.

25. Avgerinou C, Alamanos Y, Zikos P, Lampropoulou P, Melachrinou M, Labropoulou $\mathrm{V}$, et al. The incidence of myelodysplastic syndromes in Western Greece is increasing. Ann Hematol. 2013;92(7):877-87.

26. Lau LG, Chng WJ, Liu TC, Tan LK, Ong KH, Mow BM, et al. Clinico-pathological analysis of myelodysplastic syndromes according to French-American-British classification and international prognostic scoring system. Ann Acad Med Singap. 2004;33(5):589-95.

27. Haase D, Germing U, Schanz J, Pfeilstocker M, Nosslinger T, Hildebrandt $B$, et al. New insights into the prognostic impact of the karyotype in MDS and correlation with subtypes: evidence from a core dataset of 2124 patients. Blood. 2007;110(13):4385-95.

28. Rashid A, Khurshid M, Shaikh U, Adil S. Chromosomal abnormalities in primary myelodysplastic syndrome. J Coll Phys Surg-Pak JCPSP. 2014;24(9):632-5.

29. Li L, Liu XP, Nie L, Yu MH, Zhang Y, Qin TJ, et al. Unique cytogenetic features of primary myelodysplastic syndromes in Chinese patients. Leuk Res. 2009;33(9):1194-8.

30. Gmidene A, Sennana H, Fenaux P, Laatiri A, Zarrouk M, Bouaziz H, et al. Cytogenetic abnormalities in Tunisian de novo myelodysplastic syndrome: a comparison with other populations. Leuk Res. 2008;32(12):1824-9.

31. Parlier V, van Melle G, Beris P, Schmidt PM, Tobler A, Haller E, et al. Hematologic, clinical, and cytogenetic analysis in 109 patients with primary myelodysplastic syndrome. Prognostic significance of morphology and chromosome findings. Cancer Genet Cytogenet. 1994;78(2):219-31.

32. Papaemmanuil E, Gerstung M, Malcovati L, Tauro S, Gundem G, Van Loo P, et al. Clinical and biological implications of driver mutations in myelodysplastic syndromes. Blood. 2013;122(22):3616-27.

33. Sloand EM, Pfannes L, Chen G, Shah S, Solomou EE, Barrett J, et al. CD34 cells from patients with trisomy 8 myelodysplastic syndrome (MDS) express early apoptotic markers but avoid programmed cell death by up-regulation of antiapoptotic proteins. Blood. 2007;109(6):2399-405.

34. Heng HH, Regan SM, Liu G, Ye CJ. Why it is crucial to analyze non clonal chromosome aberrations or NCCAs? Mol Cytogenet. 2016;9:15.

35. Imataki O, Kubo H, Takeuchi A, Uemura M, Kadowaki N. Nonclonal chromosomal alterations and poor survival in cytopenic patients without hematological malignancies. Mol Cytogenet. 2019;12:46.

\section{Publisher's Note}

Springer Nature remains neutral with regard to jurisdictional claims in published maps and institutional affiliations. 